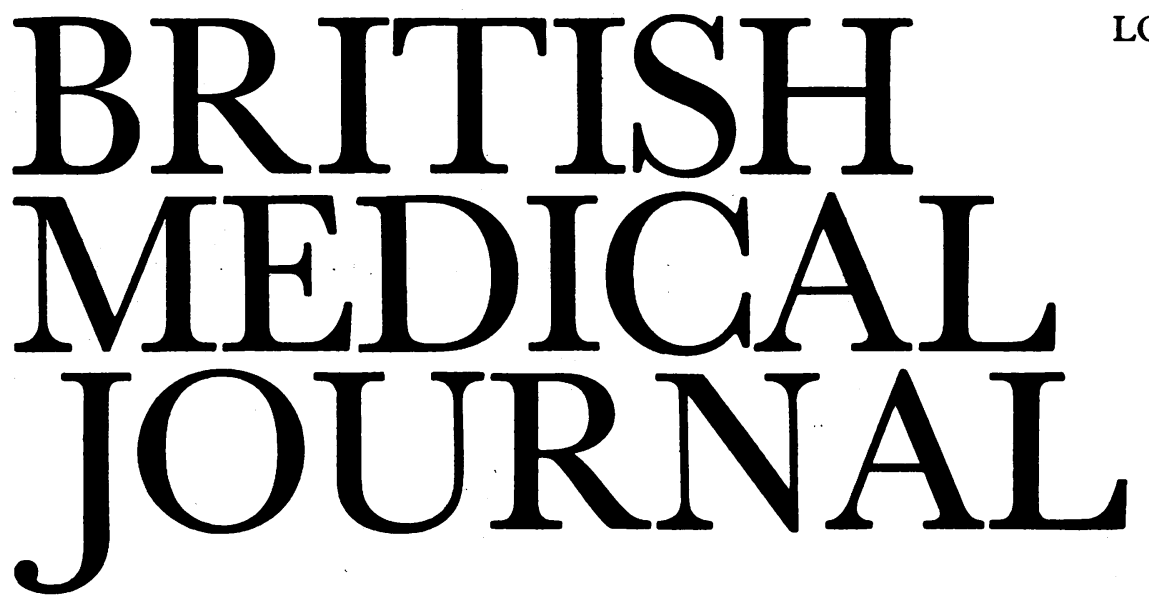

\title{
Hospital medical staffing: our hope for years to come
}

How does the National Health Service reconcile a good service for patients with effective postgraduate training for doctors and a healthy research programme? Until recently a combination of tradition, haphazard evolution, and serendipity has enabled the service to muddle through. The independent, authoritarian ethos of a consultant led hospital service has survived because much of the routine workload has been carried by junior staff "in training," many of them forced to remain too long in the training grades because of a lack of career openings. This often prolonged dual role of junior staff has caused great frustration, but the system has survived because, to our shame, overseas doctors have provided a cushion. This complacent and comfortable option is ending. Some districts are at their wit's end to provide viable orthopaedic and accident and emergency services; the supply of locums through burgeoning locum agencies has become a ramp; and young doctors are seriously worried about their careers and the persisting promotion blocks.

On these terms the NHS is not safe in anybody's hands. Possible solutions to the unsatisfactory career structure have been proposed for many years. ${ }^{1}$ Nothing came of the progress reports of the early $1970 \mathrm{~s}^{2-4}$ and though the important recommendations of the Short report ${ }^{5}$ had strong government support the latest delicate admission of the Department of Health and Social Security is that "progress in reforming hospital medical staffing has not been rapid." This, briefly, is the background to one of the most important documents on the NHS for many years - the implementation report on Hospital Medical Staffing: Achieving a Balance, published on 27 October (31 October, p 1152). ${ }^{6}$

This detailed report, the outcome of negotiations between teams from the Joint Consultants Committee and the DHSS, with representatives from the regional health authority chairmen and academic medicine, will be distributed widely. The Joint Consultants Committee has already discussed it, with the chairman, Mr A H Grabham, wholed the profession's team in the discussions, reporting that implementation was going ahead and describing the proposals "as the best and most realistic that could be achieved at present" (p 1219). The report sketches the origins of the initiative and lays down plans. Health authorities will be accountable for maintaining a $2 \%$ expansion in the number of consultants, and 100 pump priming posts in medicine, surgery, and orthopaedics are to be introduced over two years. Earlier appointment of consultants is to be expected as postgraduate training gradually shortens, and consultants will provide more direct care for patients than they have traditionally done. Early and partial retirement of consultants will be facilitated, and "career" registrar posts for British graduates and "visiting" posts for overseas doctors are to be introduced but with the designation applying to individuals rather than to posts. There will also be an overall reduction in the number of registrar posts, although no initial restriction will be placed on the number of visiting registrarships. Regions will be given quotas for "career" posts by mid-1988, and substantial reductions in most specialties are planned compared with the number of United Kingdom graduates now in post. Regional health authorities will hold the contracts for all registrar posts, and the numbers of academic and research posts at registrar level will be reduced proportionately to NHS posts, but with a central reserve of posts to retain flexibility.

A monitored relaxation of the ceiling on senior house officer posts is to take place. A controversial innovation, critical to the success of the whole plan, will be the new staff grade-described as an intermediate service grade in the previous document-to be introduced gradually from late 1988 by 200 posts a year for the first five years to a maximum of not more than $10 \%$ of the number of consultants. Strict controls and careful monitoring of this new grade are promised: without these it could soon be discredited. The arrangements for the staff grade mean that it will be appropriate for daytime work in some specialties such as ophthalmology, for shift work, or for continuous out of hours activity in, for example, accident and emergency departments. The review body will be invited to price the grade. The most important points to be emphasised about the staff grade are the small numbers of posts to be released initially, the intention to watch over them with care, and the dangers of misusing the grade in various ways.

Apart from general practitioners, there will be no further clinical assistant appointments of six sessions and above, which health authorities have increasingly used to fill gaps in the service. To ensure that service needs are covered in the new structure "safety net" arrangements are proposed that should ensure that each of a district's acute services will have the support of three or four doctors-registrars, senior registrars, experienced senior house officers, or staff (intermediate service grade) doctors. General medicine, general surgery, trauma and orthopaedics, obstetrics and gynaecology, paediatrics, anaesthesia, and some surgical specialties are expected to be covered by these arrangements.

The NHS has wasted skilled manpower by not providing 
adequate careers advice for young doctors. In future careers advice and counselling will be made available, particularly for those doctors who are stuck. Such doctors may be given a four year extension of contract or may be recommended for retraining in a new specialty or for general practice, for the staff grade, or for regrading as associate specialist. Exceptionally, they may be offered a five year rolling contract. For British graduates advice and counselling will include mandatory referral to the clinical tutor for those who after two years as a senior house officer in the same specialty have not been shortlisted for a career registrar post. When, as is planned, the total length of registrar and senior registrar training is reduced these grades are likely to merge into a single "higher" training grade, a sensible development. An appendix giving some manpower projections based on simple modelling similar to previously published work ${ }^{78}$ draws the inevitable conclusion that a "do nothing" option can lead only to longer and more disorganised training, greater dependence on clinical assistants, and increasing difficulty in maintaining clinical services.

The report also analyses responses to the consultation process. Most comments related to the proposed registrar arrangements and the proposed service grade. In response to anxieties among doctors about discrimination the report makes the point that positive or "reverse" discrimination may be necessary to ensure that registrar posts go to visiting overseas doctors rather than vitiating the quota by appointing more British graduates. Emphasis is laid on the minimum requirement for the intermediate service grade being three years' experience as a senior house officer, with a warning that the grade must not be abused at the expense of consultant posts or of women doctors (and others) who merit higher training and consultant status. An academic and research subgroup has prepared proposals which should allay worries about research that surfaced when the original document was published. A joint statement is promised from the DHSS, Joint Consultants Committee, the Committee of Vice Chancellors and Principals, and research interests.

Concentration on a single aspect of the career structure will not overcome manpower problems and nor will utopian schemes that have no chance of gaining general support in the NHS. What is needed is a coordinated package of proposals realistically, but not cynically, calculated to prove acceptable to all concerned. This is the strength of Achieving a Balance. All the moves are in the right directions, and the timetable offers a gradual amelioration of staffing and training difficulties. There are no quick remedies, and patience and tolerance will be needed. For example, overseas doctors may well not seek training in the specialties where their services are most sought. Strong pressure for the creation of more senior house officer posts is to be expected, but should authorities succumb to this the average time spent in the grade will rise, thus repeating past mistakes. Aimlessness of purpose at senior house officer level and continued misuse of overseas doctors-squeezing the bulge down instead of upare real dangers. We cannot in all conscience live with a manpower structure where postgraduate training begins only at the registrar level, except for entrants to general practice. It will be better to broaden the use of six month senior house officer modules beyond general practitioner training to give, in effect, a second preregistration year to everyone, with further modules to afford "equivalent experience" in specialty training.

The volume of work in handling all registrar contracts will be an administrative headache for large regions. Further resources will be needed to support postgraduate deans, regional advisers, training committees, and regional health authorities in the detailed planning and monitoring of rotations and the progress of doctors passing through them. The commitment to overseas doctors-namely, that visiting registrar training will be equal in scope and quality to career training-must be honoured. Altogether, the reform of the registrar grade in the package is fundamental to the success of the whole. Colleges and faculties might well consider again the advisability of giving general professional training recognition to rotational programmes, with scope for individual variation, rather than to separate jobs. This would certainly strengthen the hand of regional organisations and lead to valuable collaboration with them.

If the proposals in the implementation report are to succeed careful control and good public relations are vital. When he gave evidence to Renée Short's Social Services Committee, Sir George Godber, former chief medical officer at the DHSS, spoke of the need to proselytise, saying of the 1971 progress report that if he and others "had really gone around the country and tried to sell it, I believe we would have succeeded." Belatedly, doctors and the NHS have another chance to recognise what may be our last hope for years to come to develop a manpower structure that fulfils the NHS's service needs and doctors' career aspirations.

Director,

J PARKHOUSE

Medical Careers Research Group,

Churchill Hospital,

Oxford OX3 7L

1 Parkhouse J. A new look at anaesthetics. London: Pitman's Medical Publications, 1965.

2 Anonymous. Hospital staffing structure (medical and dental). Progress report on discussions between representatives of the health departments and the Joint Consultants Committee. BrMed f 1969;iv(suppl):53-6.

3 Anonymous. Hospital staffing structure (medical and dental) second progress report. $\mathrm{Br}$ Med $\mathcal{J}$ 1971;iii(suppl):119-21.

4 Anonymous. Hospital staffing structure (medical and dental) third progress report. $\mathrm{Br} \mathrm{Med} \mathrm{J}$ 1972;iii(suppl): 143-6.

5 Social Services Committee. Fourth report from the social services comminee 1980-81: medical education with special reference to the member of doctors and the career structure in hospitals. London: HMSO, 1981. (HC31-I.)

6 Department of Health and Social Security, Joint Consultants Committee, Chairmen of Regional Health Authorities. Hospital medical staffing: achieving a balance. London: DHSS, 1986.

7 Parkhouse J. Simple model for medical manpower studies. Br Med $\mathcal{f}$ 1977;2:530.

8 Parkhouse J. Medical manpower in Britain. Edinburgh: Churchill Livingstone, 1978.

9 Social Services Committee. Fourth report, 1980-81 session, volume 3: minutes of evidence. London: HMSO, 1981:636.

\section{Psoriatic science}

On an average full double decker bus three people have psoriasis. In north west Europe the phenotypic prevalence is $2-3 \%{ }^{1-3}$ but as psoriasis begins at a mean age of 28 years ${ }^{4}$ the genotypic prevalence is nearer $5 \% .^{5}$ This common disease is still not fully understood, but recent studies have begun to unravel its pathogenesis.

The red scaly patches of psoriasis ${ }^{6-9}$ are characterised by inflammation ${ }^{10}$ and by hyperproliferation of cells in the epidermis. ${ }^{11-14}$ Away from the patches, in the apparently normal skin, epidermal cells are also hyperproliferative ${ }^{12} 14$ but there is no inflammation. Any primary biochemical defect should account for hyperproliferation of epidermal cells. It should be specific for psoriasis, be present throughout the skin, and be absent from other inflammatory or proliferative diseases. 